\title{
The study of emotional processes in communication: II. Peripheral blood flow as an indicator of emotionalization
}

\author{
STEFAN JOSSEN, MARIE-LOUISE KÄSERMANN, ANDREAS ALTORFER, \\ KLAUS FOPPA, HEINRICH ZIMMERMANN, and HANS-PETER HIRSBRUNNER \\ University of Bern, Bern, Switzerland
}

\begin{abstract}
Traditional methods of analyzing human peripheral blood flow (PBF) do not account for its continuous nature or small-scale variation. Sequel transformation is presented as a new methodology for measuring these variations. This analysis generates a richer record of aspects of activation of the autonomous nervous system than traditional interbeat-interval (IBI) measurement. Presumably, in addition to heartbeat (i.e., IBI), other information can be extracted that is consistent with the influence of several physiological and psychological factors. This kind of variation is reflected in the PBF signal. After determining and extracting relevant events from vascular volume data generated by sequel transformation, we demonstrate the use of template analysis to analyze patterns of events as time courses of activation. All procedures are included in the computer program VASC Analyzer.
\end{abstract}

In our research (Käsermann, Altorfer, Foppa, Jossen, \& Zimmermann, 2000), we use peripheral blood flow (PBF) as an indicator of activation/emotionalization. In physiological psychology, features of circulatory activity (especially heart rate) have long been established as indicators and concomitants of relevant psychological (e.g., emotional) processes (see, e.g., Fahrenberg \& Myrtek, 1996). However, results concerning circulatory activity as an indicator of emotional processes have not been uniform. For instance, in a study comparable to ours in terms of its concern gathering on-line data of activational changes on a microanalytic level (Pennebaker, Hughes, \& O'Heeron, 1987), heart rate changes did not seem to reflect the relevant emotional changes. In contrast, in our own investigations of emotionalization during everyday conversation (e.g., Käsermann \& Altorfer, 1989; Käsermann, Altorfer, \& Jossen, 1998), circulatory activity changes systematically covaried with changes in emotionalization. Such discrepancies need to be accounted for; one possible explanation lies in the different ways such a physiological variable can be processed.

We conceive PBF as a continuously changing signal that is influenced by a multitude of factors. The inherent variability is a valuable source of information, but it makes PBF rather difficult to investigate. Specific vessel features, other organic properties, and psychological and external influences contribute to its complex variability (Pappillo

Parts of our research have been funded by the Swiss National Science Foundation (Grants 1114-043635.95/1 and 1113-051050.97/1). Correspondence should be addressed to S. Jossen, Department of Psychiatric Neurophysiology, University of Bern, Psychiatric Institutions, Bolligenstrasse 111, CH-3000 Bern 60, Switzerland (e-mail: jossen@ puk.unibe.ch; further information can be found at http://www.cx.unibe. $\mathrm{ch} / \mathrm{puk} / \mathrm{br} / \mathrm{hcl}$.html).
\& Shapiro, 1990). PBF is constantly influenced by external factors as the human body reacts to numerous environmental stimuli. For example, changes in the surrounding temperature or a sudden conflict may result in instant modulation of PBF. Therefore, PBF is an index of sympathetic and adrenergic activity (Jennings, Tahmoush, \& Redmond, 1980) as reflected equally in measures of autonomic balance (Hainsworth, 1995; van RavenswaaijArts, Kollée, Hopman, Stoelinga, \& van Geijn, 1993). At a local point of a vascular vessel, the flow is influenced by the pressure gradient along the length of the more or less elastic vessel, its diameter, and its viscosity. Viscosity relates to the density of red blood cells, which, in turn, depends on the vessel size and pressure gradients (Jennings et al., 1980).

Pressure changes, however, result primarily from the heart ejecting blood at intervals into the vessel system. The diameter of the vessel is also regulated by the autonomic nervous system through organic substances like calcium, catecholamines, or polypeptides (Crapo, 1985; Said, 1984). The sympathetic nervous system mediates abrupt alterations in blood flow. Most factors change as a function of organic and psychological processes (e.g., experienced deviation from a standard mood; Käsermann et al., 2000) and their complex interaction. On all levels of the interacting factors, great individual differences are to be expected.

Traditionally, the information gathered from recorded PBF and from an electrocardiogram is essentially the same. This information is the interbeat interval (IBI). IBIs indicate the duration of consecutive periods transformed into frequency of heartbeats per minute. With regard to PBF, this approach reduces a continuous signal to a set of discrete events. Common methods for measuring IBIs implement a pragmatically determined trigger or a peak de- 
tection algorithm, both of which guarantee the identification of successive periods in the signal. In other words, these procedures ignore other information potentially inherent in PBF (Berne \& Levy, 1986; Siddle \& Turpin, 1980; Turpin, 1989).

Our approach treats the same basic data in an alternative way. Instead of a two-dimensional representation of the photoplethysmographic output, we use a three-dimensional one. It is achieved by sequel transformation (a vectoranalytic transformation) of the analogous data, and it yields the sequel as a unit of duration and amplitude of a period (Hirsbrunner, 1979). By representing and scaling similar output data of a photoplethysmograph in an alternative way, we augment variability and therefore can study additional aspects of activation changes.

Here we present three computer-assisted methods that account for the continuous character of PBF. The first method is sequel transformation, which prepares continuous PBF data for a quasi-continuous measurement of periods. The result of this transformation is vascular volume data (VVData). The second method is the extraction of relevant events from VVData, resulting in a quantification of vascular volume events (VVEvents). Finally, we analyze time courses of VVEvents with the third method, template analysis. All three methods are part of our computer program, VASC Analyzer (Jossen, Altorfer, Käsermann, Foppa, \& Zimmermann, 1998). ${ }^{1}$

\section{METHOD}

\section{Recording PBF}

We register PBF with a small photoelectric infrared transducer (photoplethysmograph) from PowerLab (Data
Recording System for Windows 95/98/NT and Mac OS, Chart Software 3.6, ADInstruments, 1999) that is attached to a finger of the person's nondominant hand. The minor restrictions inflicted by the apparatus can be regarded as a constant factor for all subjects and therefore can be dismissed (Altorfer, Jossen, \& Würmle, 1997). According to Porges and Bohrer (1990), the sampling rate for digital recording must be fast enough to prevent aliasing. "Aliasing may be avoided by sampling faster than twice the frequency of the highest frequency potentially present in the signal" (p. 751). With a maximum possible heart rate frequency of 240 beats per minute, this means, for instance, sampling at $8 \mathrm{~Hz}$ at least. A sampling rate of $100 \mathrm{~Hz}$ is used, which is considered to be sufficient for the digital recording of the data in question. The light-emitting diode in the sensor transducer produces infrared light, which is reflected to excite the phototransistor. Hence, the amount of reflected light is converted to an electrical signal, which represents the actual volume of PBF.

\section{Transformation of Continuous PBF (Sequel Transformation)}

Although created by a mixture of frequencies, the recorded PBF wave can be conceived of as consisting of three components. The first part is the base oscillation, which reflects the heart activity in the vessels (heart rate and other periodic influences, including respiration and blood pressure) as modulated by different a-periodic factors, including metabolic demands (Porges \& Bohrer, 1990, p. 717). The second part consists of low-frequency overlaps, which are formed, for example, by respiratory movements. The third part consists of high-frequency overlaps,

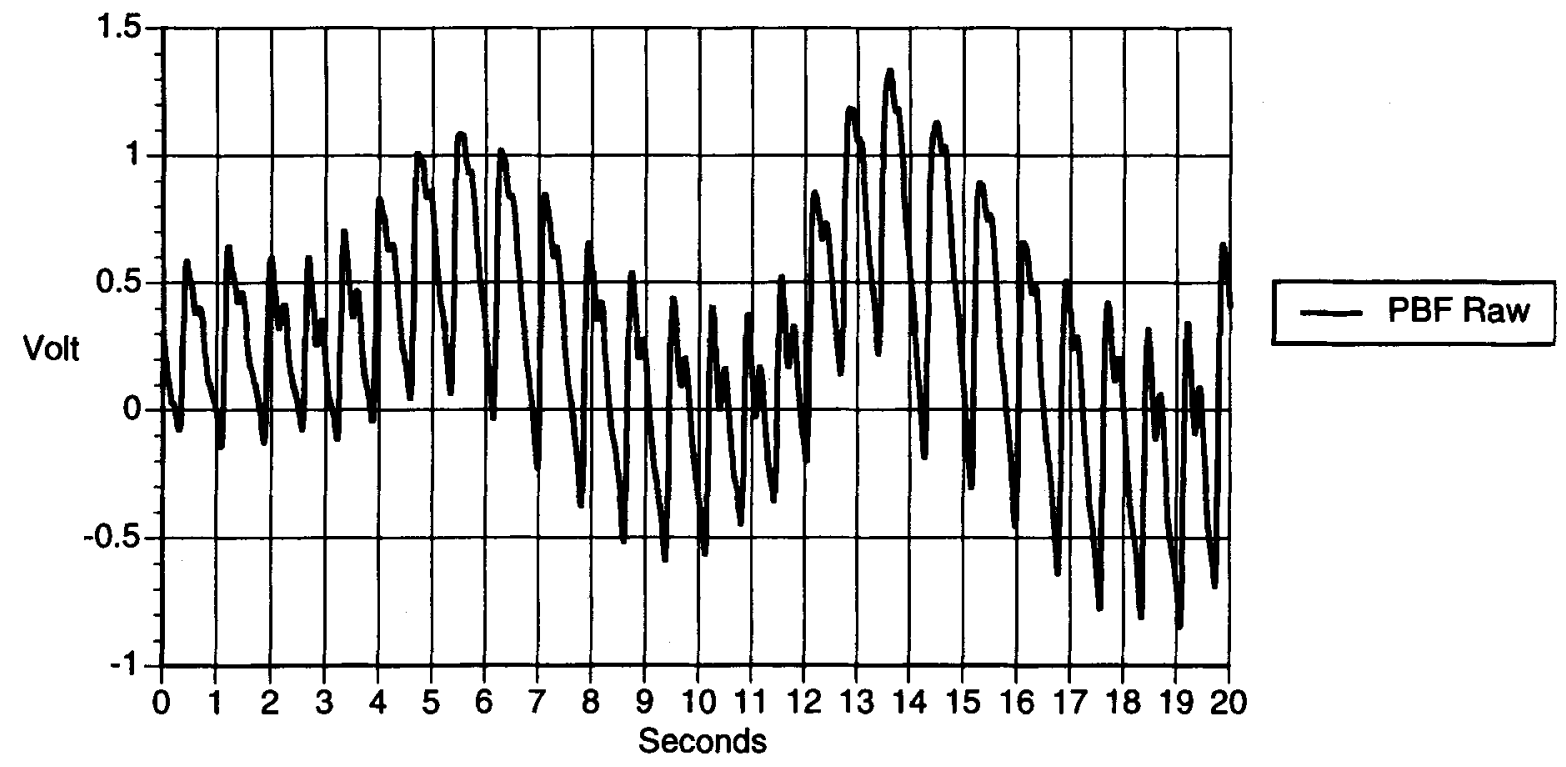

Figure 1. Peripheral blood flow (PBF) data recorded with a photoplethysmograph and Chart 3.6. Software from PowerLab. 
caused, for instance, by the noise of the recording equipment. After appropriate prefiltering to eliminate highand low-frequency overlaps from the data, sequel transformation enables us to focus on changes of the PBF that are due to activation of the autonomous system.
The original PBF signal (Figure 1) is processed in two steps. First, it is passed through a succession of pragmatically determined band-pass filters (Figure 2C). Each band-pass filter is a combination of a low-pass filter (suppression of high-frequent constituents; Figure $2 \mathrm{~B}$ ) and a
A

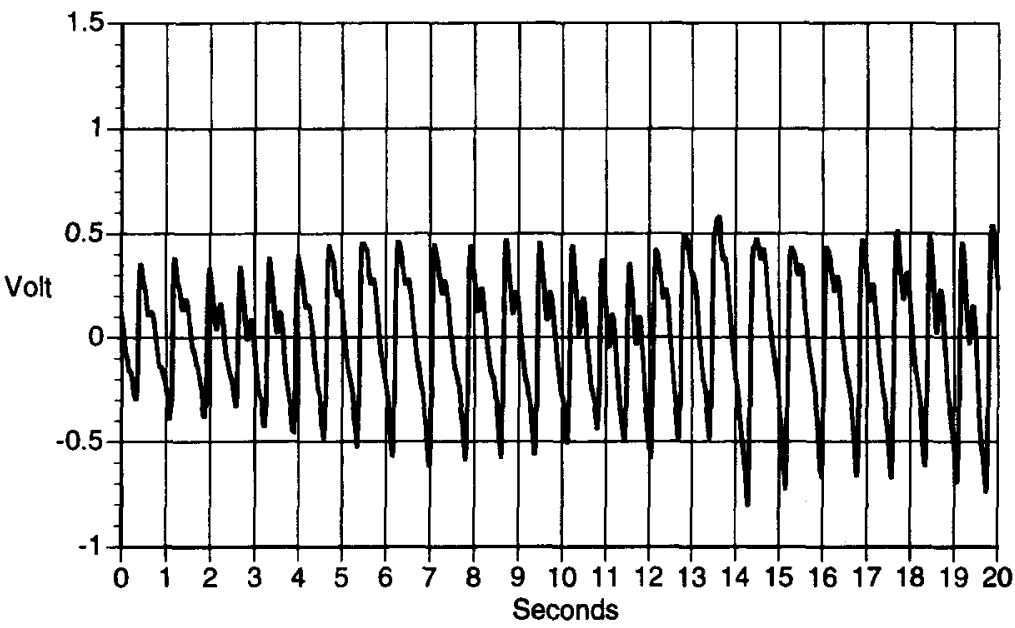

B

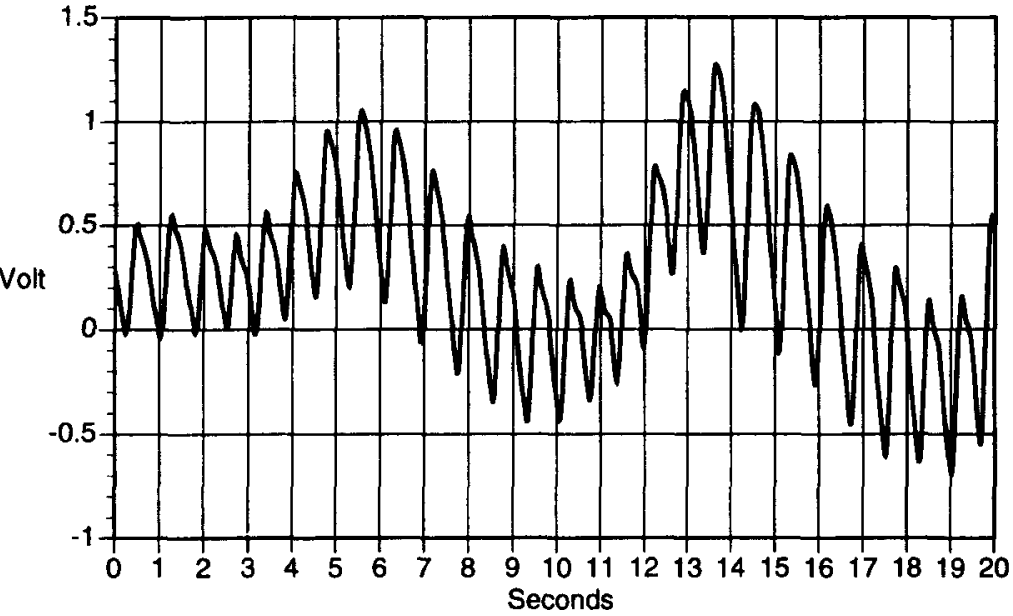

C

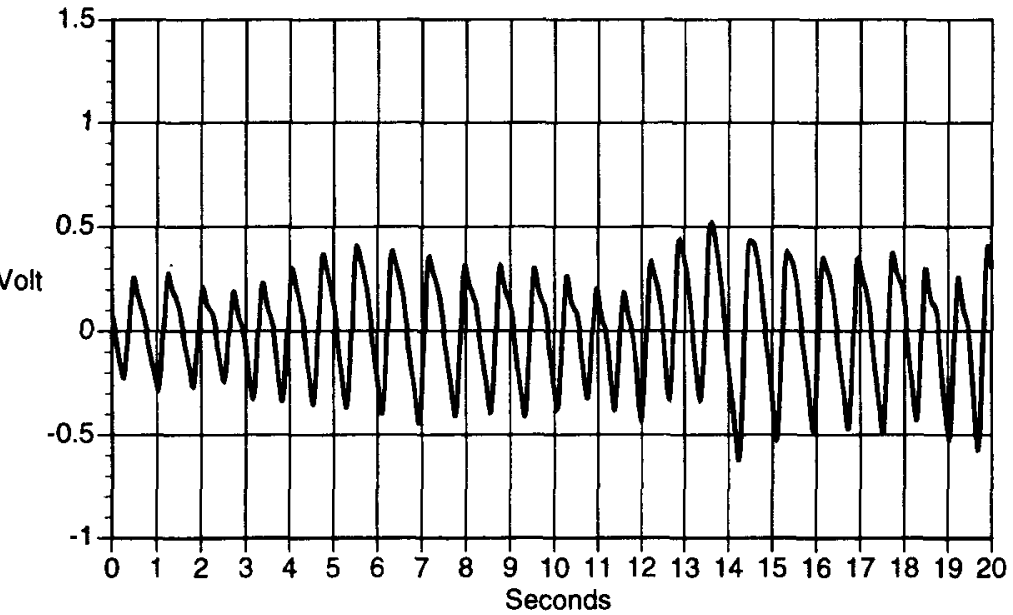

PBF Highpass

PBF Lowpass

Figure 2. Peripheral blood flow (PBF) data, high-pass (A), low-pass (B), and band-pass filtering (C) to get clear zero crossings. 


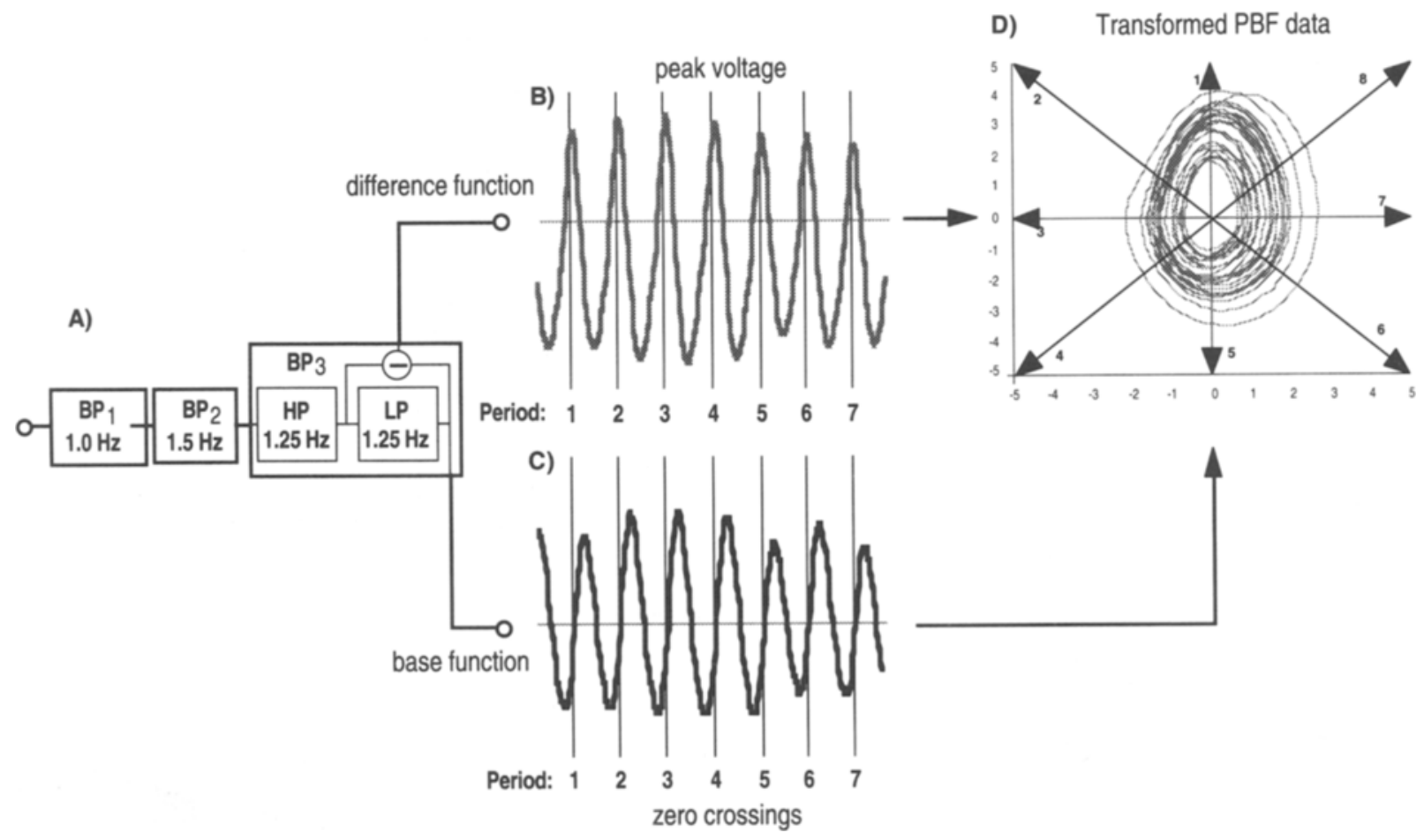

Figure 3. Sequel transformation of peripheral blood flow (PBF) data: (A) Filters (BP, band-pass; HP, high-pass; LP, low-pass); (B) difference function; (C) base function; and (D) two-dimensional display with axes and Sectors $1-8$ for measuring periods and amplitudes.

high-pass filter (suppression of low-frequency constituents; Figure 2A; Tietze \& Schenk, 1988). This type of filtering is applied in order to neutralize the detrimental effects that high- and low-frequency overlaps may have on the determination of zero crossings by adding deficient axis crossings in the original curve (Figure 1). Such prefiltering is also routinely used in the traditional determination of triggers. The output of the band-pass filtering is presented in Figure 2C.

Second, to allow for the two-dimensional sequel representation of PBF, the output of the last band-pass filter is fed back to calculate the difference function. This is easily done by calculating the difference between output and input of the low-pass filter in the last band-pass stage (Hilbert, 1985). The resulting waves bring about an exact $90^{\circ}$ phase shift for all spectral components of the PBF data (Altorfer, Hirsbrunner, \& Käsermann, 1990; Hirsbrunner, 1979). Subsequently, data from the difference function are drawn onto the $y$-axis and the data from the base function are drawn onto the $x$-axis of a two-dimensional graph (Figure 3). Since discrete time sampling is used, every point of the difference function has its corresponding partner in the base function with the same time value. In the three-dimensional display, the running time is added in the $z$-axis (Figure 4).

With this transformation, the succession of peaks is no longer the sole feature visible, as in the traditional twodimensional representation. Instead, the successive patterns of consecutive periods and their variations in time become apparent. Projecting this record of PBF changes into a two-/three-dimensional system yields two types of measures of what we call vascular volume data (VVData). The first measure is the duration of a sequel as measured from each scaling point. The second measure is the amplitude of the sequel at the same point in time.

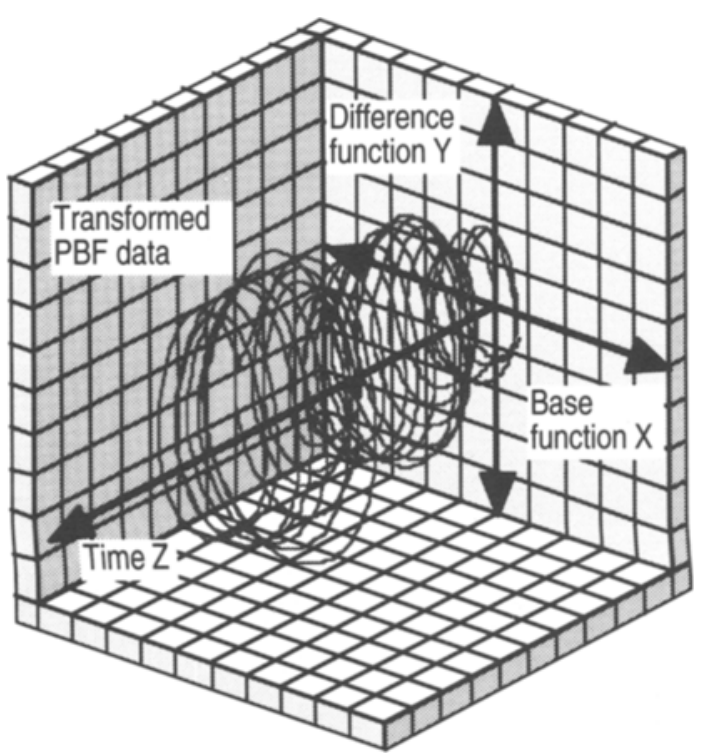

Figure 4. Sequel transformation: three-dimensional display of the peripheral blood flow (PBF) data. 


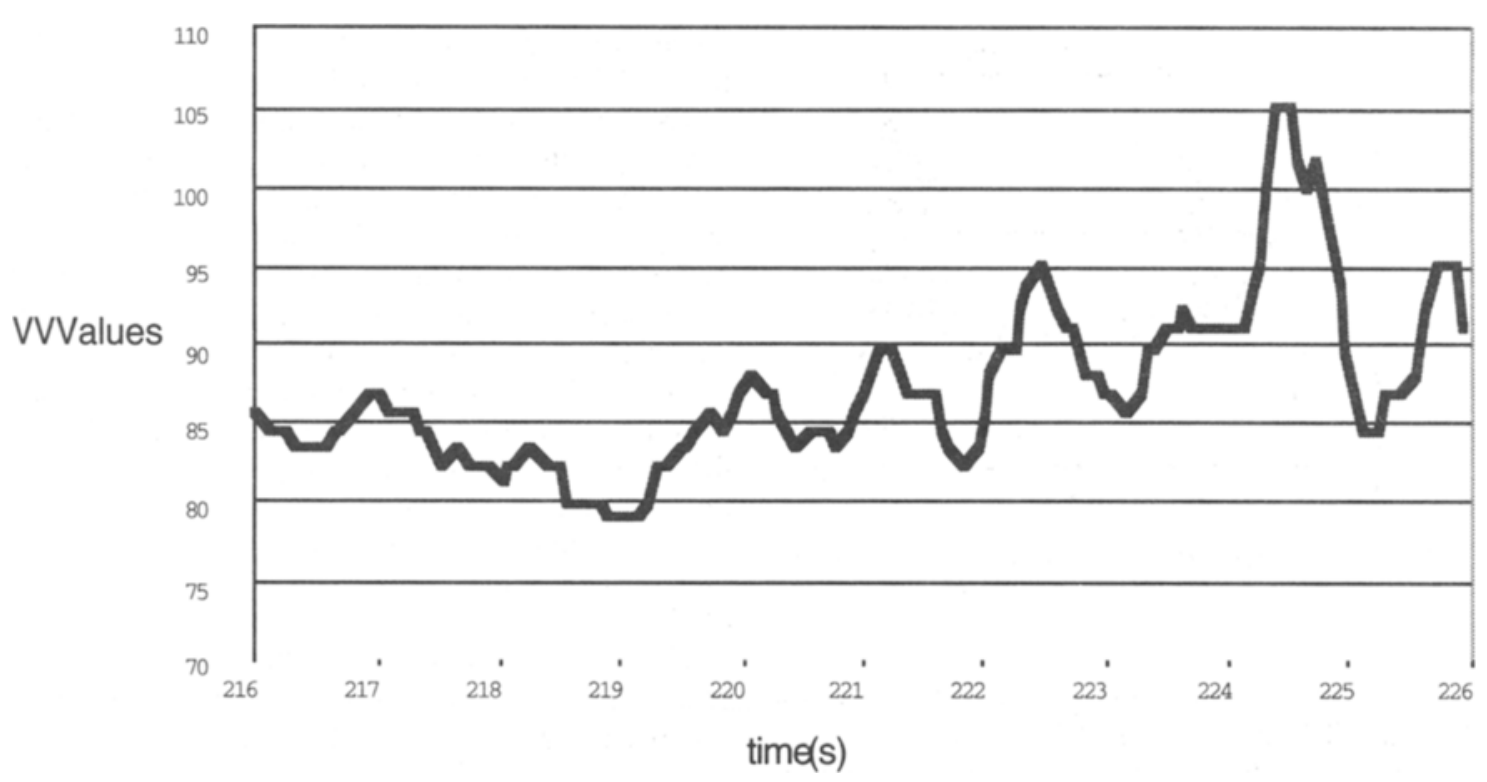

Figure 5. Vascular volume data (VVData): Higher vascular volume values represent higher levels of autonomous activation.

The two-/three-dimensional representation of the sequel graph permits the identification of any position of the phase (Figure 3D). One circle on the graph represents a sequel; this circularity is evidence of the periodic character of PBF. This kind of representation makes it possible to measure the duration of the period (i.e., the time elapsed since the previous crossing of the same sector) or the amplitude (distance to zero) independently of the peak. In principle, this can be done quasi-continuously at every defined angle. By multiplying the measurement of the features of a period (especially duration and amplitude), one can extract information about variability, which is more meaningful than just information about heart rate frequencies. Thus, an adequate number of angles is determined as a function of an informed guess about the information one expects to be able to extract from the signal. One can use these expectations, in turn, to answer important psychological and physiological questions. At present we use eight angle positions, dividing the circle into eight sectors (Johnson sequences, Beauchamp, 1984). This choice was determined by our wish to represent activation changes in events of short duration (e.g., utterances in a dialogue with an average duration of $2 \mathrm{sec}$ ) as time series.

Sequel transformation generates a new kind of data, which we call vascular volume data (VVData). A steady PBF of $1 \mathrm{~Hz}$ ( 60 beats per minute) would produce constant vascular volume values (VVValues) of 60 . Higher VVValues would represent higher levels of autonomous activation (Figure 5).

\section{Identification of Relevant Changes in the PBF Signal}

Detecting biologically unlikely events. The recording of PBF in a natural situation without constraints has po- tential drawbacks. For example, movements of the measured fingertip or coughs can distort the signal. For as yet unidentified reasons, the recording system may produce similar distortions. These distortions, which appear as extremely high VVValues, are too extreme to have a

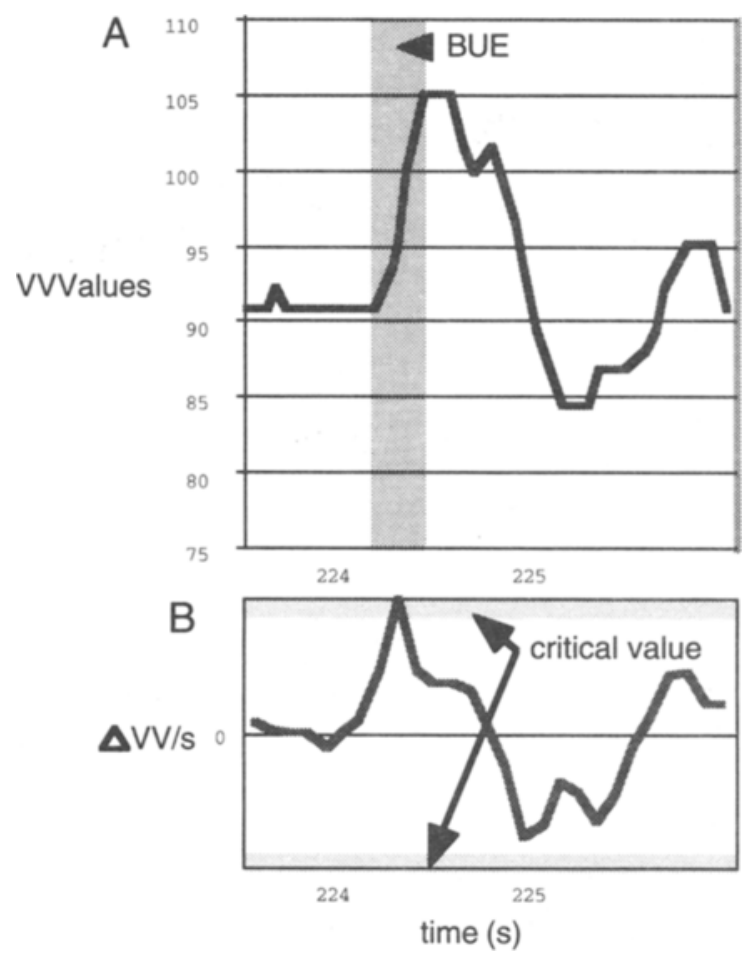

Figure 6. Detection of biologically unlikely events (BUEs): $A$ BUE is detected if the acceleration of the Vascular Volume Data (VVData) surpasses a critical value: (A) Original VVData; (B) display of the acceleration $(\Delta \mathrm{VV} / \mathrm{s})$ of the VVData. 


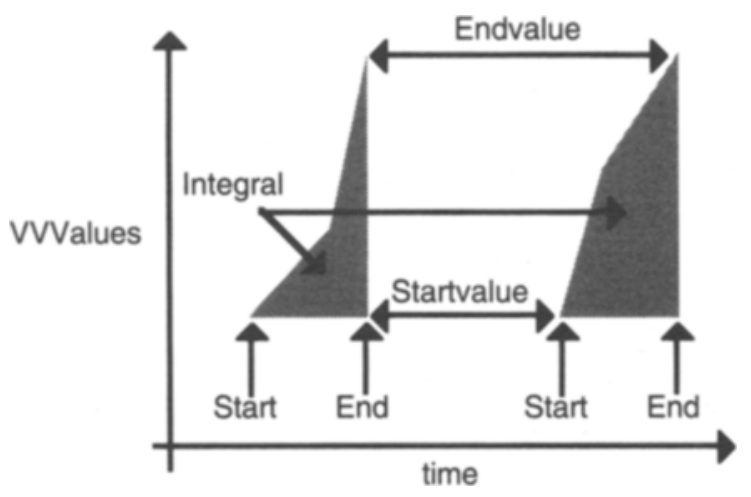

Figure 7. Polygon representing a relevant vascular volume event.

biological background. We call these data biologically unlikely events (BUEs). To detect BUEs, all the VVData are processed by applying specific automatic detection criteria. These criteria permit a maximum acceleration rate (Figure 6) and prevent an excessive number of successive changes in a positive or negative direction. BUEs are blocked from further analysis.

Extracting relevant vascular volume events. The next step in the process of analyzing VVData is extraction of relevant VVEvents. A VVEvent represents a relevant change in the total activation of the autonomic nervous system. What is considered as "relevant" is a result of experience and prevalidation studies (see Käsermann \& Altorfer, 1989). First, the automatic event detection algorithm builds a moving average over the whole data set. Second, the difference between successive VVValues and the time between two adjacent points serves to express the acceleration of the wave. The relevant VVEvents are then extracted using a set of criteria comparable to those used in motion detection, as described in Altorfer et al. (2000).

The critical values of each of the variables of such a set of criteria can be adjusted according to the needs of the specific research question. This guarantees an adequate level of sensitivity for detecting smaller or bigger events. The beginning of a relevant event is indicated when the acceleration of VVData exceeds a critical value. The end

A

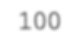

VVData

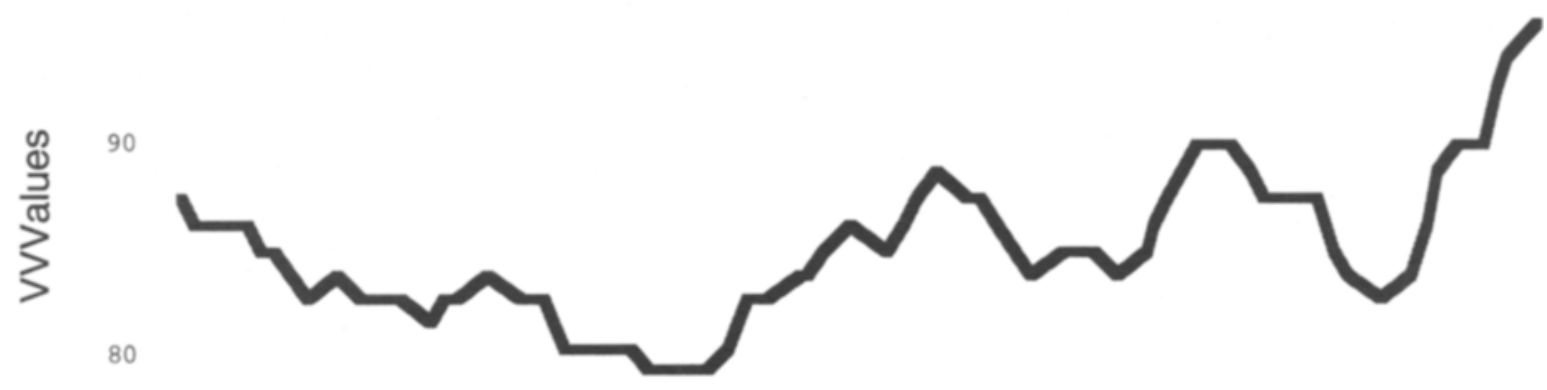

B 100

218

219

220

221

222

\section{VVEvents}
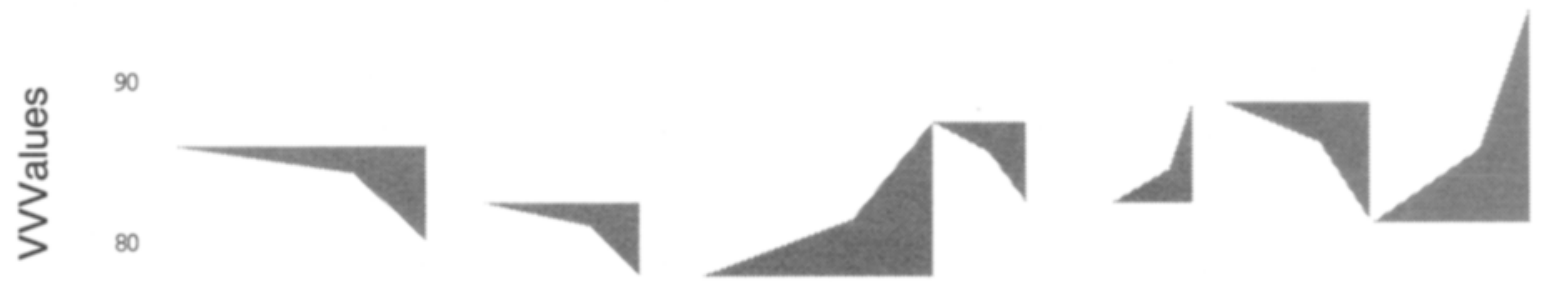

70

\section{time (s)}

Figure 8. Extraction of relevant vascular volume events (VVEvents) from vascular volume data (VVData). (A) Original VVData and (B) relevant VVEvents within the same time. 
is indicated when the acceleration of VVData drops below a critical value. The change of VVValues from one VVdata point to the next must attain a certain amount, and the duration of the change must have a minimal length. A VVEvent can be represented graphically by a polygon, where the varying integral of the plane represents the amount and type (e.g., "concave" or "convex") of the ascent or descent (Figure 7). Figure 7 shows a mounting of autonomous activity. Descending autonomous activity is equally relevant. The corresponding polygon representation points downward. All VVData (Figure $8 \mathrm{~A}$ ) can be displayed as a succession of relevant VVEvents (Fig-

A) FIND mean course of activation and selection of a TEMPLATE for template analvsis

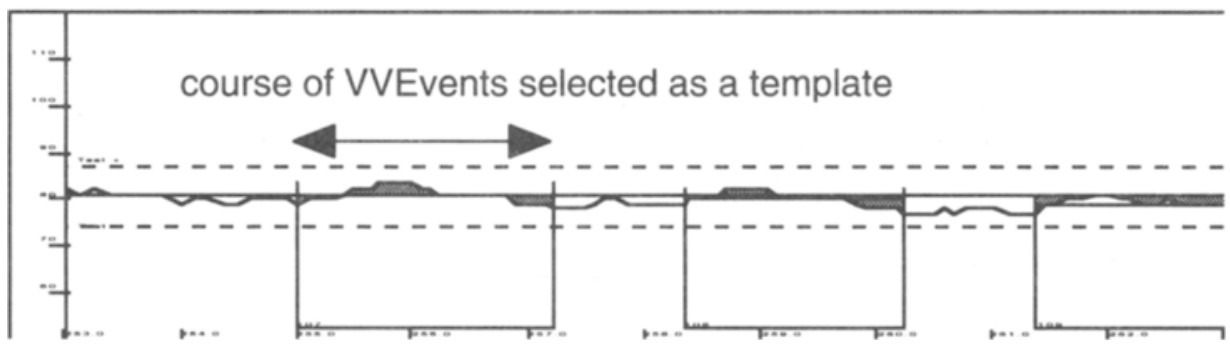

B) SEARCH for PERIODICITY of correlation function resulting from similarities between selected template and course of VVEvents (.r $=.95$

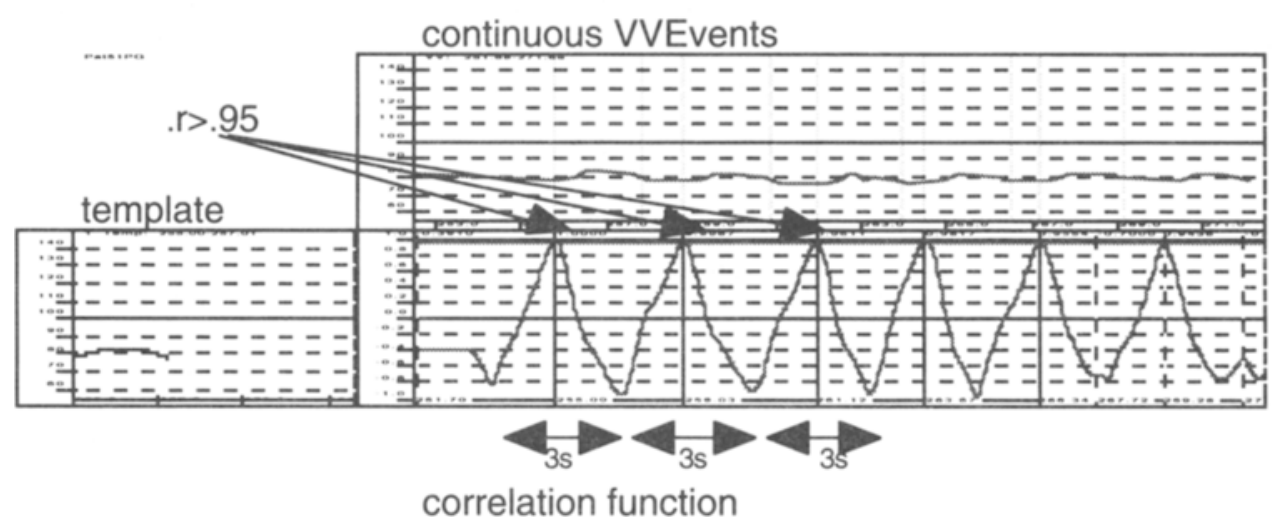

C) DETERMINE features of DEVIATION and compose a continuous index of deviation

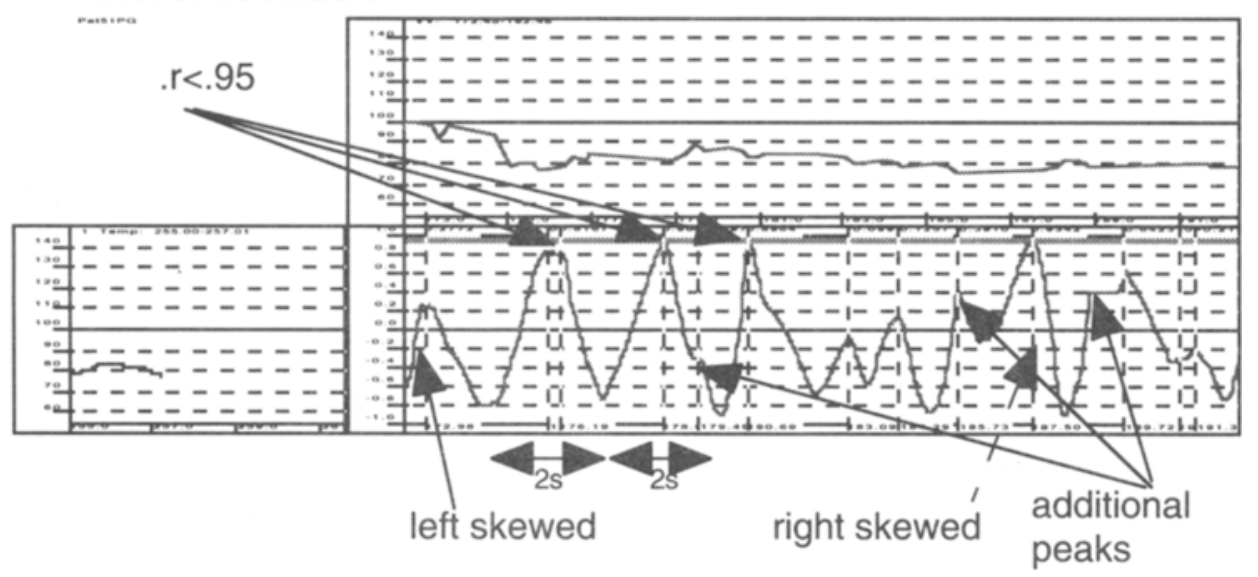

Figure 9. Template analysis: Steps in processing standard and deviation courses of vascular volume events (VVEvents). 
ure $8 \mathrm{~B}$ ). The data are thereby greatly reduced but still contain all relevant information.

\section{Analyzing Time Courses of Activation: Template Analysis}

In processing variation in VVData, we are not primarily interested in detecting single events, but rather, meaningful groups of events. These events form patterns of courses of activation that accompany relevant (e.g., communicative) episodes. Any section of successive VVEvents (Figure 9A), selected on the basis of specified (e.g., psychologtemplates is based on the following rationale (Figure 9): Similarity and difference between any of two templates or any part of an entire set of VVEvents can be assessed with the help of correlation procedures. Templates consisting of the same number of data points can be considered as two sets of values to be correlated. They are conceived to be equal or similar if the resulting correlation corresponds to $.95 \geq r \leq 1.0$. If a template is correlated with itself, the resulting correlation coefficient is always $r=1.0$. Additionally, dragging the template over the entire course of VVEvents results in a correlation function (Figure 9B). The graphical representation of this correlation function itself has a characteristic form. While working on the task empirically, we learned that as a rule, relaxation is accompanied by a sinus-like correlation function (Käsermann, 1998; Porges \& Bohrer, 1990, e.g., p. 713). In contrast, the correlation function during critical episodes is characterized by a modification of this periodicity consisting of shorter durations of single periods and/or irregular durations between subsequent periods of the correlation function. Such deviations from periodicity can easily be quantified (e.g., with regard to the regularity, the time duration of the period, or the height of correlation; Figure 9C).

The conceptual background of the analysis of templates (especially determining the similarity or difference between any two templates) is provided by the standard deviation principle (see Käsermann et al., 2000). Comparing the correlation function of a template from a standard course of activation with that from a course during potentially critical events helps determine whether a predicted activation change has occurred. For instance, we collected evidence indicating that template analysis can distinguish between patterns of relaxation of healthy persons and of medicated schizophrenics; furthermore, within the two diagnostic groups, patterns of relaxation are distinct from patterns during critical communicative events (Käsermann, 1998). This finding recurred in a number of single-case studies (Käsermann, 1998; Käsermann, Altorfer, \& Jossen, 1998).

\section{CONCLUSION}

Although the original PBF is (visually) dominated by the heartbeat, it presumably inherits - in addition to heart rate variability (see Gottman, 1990, for an overview on statistical methods) - a multitude of other information that is usually not analyzed (Kitney \& Rom- pelman, 1980). This information is contributed by various factors modifying the volume of the peripheral vessels. It can be extracted, so we assume, if the registration of features of periodicity is not restricted to capturing IBI, but is more highly resolved. It can be argued, therefore, that the variable of delay or acceleration in phase (phase angle) and increasing or decreasing wave forms (pattern changes) are as important as what is measured with IBI (Crapo, 1985; Said, 1984). With the VASC Analyzer program, we introduce procedures that are able to capture this variation during brief events (e.g., communicative utterances) and also to transform and analyze vast amounts of PBF data quickly. Throughout all levels of the analysis, we maintain control of the criteria settings and their immediate effect on subsequent proceedings. Part of our work consists in validating these criteria.

Looking at the autonomic nervous system from this perspective makes it possible to formulate hypotheses about factors modifying human activation. This conviction rests on the assumption that variation extracted from the PBF by means of measuring VVData can be explained by detecting the factors systematically controlling its occurrence. With regard to communicative factors, this claim can be supported (Altorfer et al., 2000; Käsermann et al., 2000; Käsermann, Altorfer, \& Hirsbrunner, 1998; Zimmermann, Käsermann, Altorfer, Jossen, \& Foppa, 1998). However, it is of course not within the scope of psychological research to monitor physiological concomitants of activation changes.

\section{REFERENCES}

ADINSTRUMENTS, LTD. (1999). PowerLab: Data Recording System for Windows 95/98/NT and Mac OS, Chart Software 3.6 [Computer software]. (Available from Grove House, Grove Road, Hastings, East Sussex TN35 4JS, U.K.)

Altorfer, A., Hirsbrunner, H.-P., \& Käsermann, M.-L. (1990). Messung psychophysiologischer Variablen während Gesprächen. Die Quantifizierung des Pulsvolumengeschehens. Zeitschrift für Psychologie, 198, 293-308.

Altorfer, A., Jossen, S., Würmle, O., Käsermann, M.-L., Foppa, K., \& ZimmermanN, H. (2000). Measurement and meaning of head movements in everyday face-to-face communicative interaction. Behavior Research Methods, Instruments, \& Computers, 32, 17-32.

Altorfer, A., Jossen, S., \& WürmLE, O. W. (1997). Eine Methode zur zeitgenauen Aufnahme und Analyse des Bewegungsverhaltens. Zeitschrift für Psychologie, 205, 83-117.

Altorfer, A., KäSERMANN, M.-L., \& Hirsbrunner, H.-P. (1998). Arousal and communication: I. The relationship between nonverbal, behavioral, and physiological indices of the stress response. Journal of Psychophysiology, 12, 40-59.

BEAUCHAMP, K. G. (1984). Applications of Walsh and related functions with an introduction to sequency theory. London: Academic Press.

Berne, R. M., \& Levy, M. N. (1986). Cardiovascular physiology. Washington, DC: Mosby.

Crapo, L. M. (1985). Hormones, the messengers of life. New York: W. H. Freeman.

FAHRENBERG, J., \& MYRTEK, M. (EDS.) (1996). Ambulatory assessment: Computer-assisted psychological and psychophysiological methods in monitoring and field studies. Seattle: Hogrefe \& Hüber.

GotTMAN, J. (1990). Time-series analysis applied to physiological data. In J. T. Cacioppo \& L. G. Tassinary (Eds.), Principles of psychophysiology: Physical, social, and inferential elements (pp. 754-774). Cambridge: Cambridge University Press. 
HaINSWORTH, R. (1995). The control and physiological importance of heart rate. In M. Malik \& A. J. Camm (Eds.), Heart rate variability (pp. 3-19). Armonk, NY: Futura.

HIL BERT, A. (1985). Taschenbuch mathematisches Grundwissen: Band II Höhere Mathematik. Frankfurt: Harri Deutsch.

Hirsbrunner, H.-P. (1979). Sequel-analysis. Ein zeitgenaues Verfahren zur visuellen Verlaufsanalyse des Sprachsignals. Unpublished doctoral dissertation, University of Bern.

Jennings, J. R., Tahmoush, A. J., \& Redmond, D. P. (1980). Noninvasive measurement of peripheral vascular activity. In E. Martin \& P. H. Venables (Eds.), Techniques in psychophysiology (pp. 69-136). New York: Wiley.

Jossen, S., Altorfer, A. Käsermann, M.-L., Foppa, K., \& ZimmerMANN, H. (1998). Computer-based analysis of physiological data in natural situations [Abstract]. In Measuring Behavior '98: Proceedings of the Second International Conference on Methods and Techniques in Behavioral Research (pp. 177-179). Wageningen, The Netherlands: Noldus Information Technologies.

KäSERMANN, M.-L. (1998). Regelverletzungen und Emotionalisierung. Auftreten und kommunikationsabhängige Modifikation von Erregung bei Gesunden und Schizophrenen. In W. Hacker et al. (Eds.), Zukunft gestalten. Forty-first Congress of the German Psychology Society [Abstract]. Munich: H. P. Klein.

Käsermann, M.-L., \& Altorfer, A. (1989). Family discourse: Situations differing in degree of stress and their physiological correlates. British Journal of Psychiatry, 155(Suppl. 5), 136-143.

Käsermann, M.-L., Altorfer, A., Foppa, K., Jossen, S. \& ZimmerMANN, H. (2000). The study of emotional processes in communication: I. Measuring emotionalization in everyday face-to-face communicative interaction. Behavior Research Methods, Instruments, \& Computers, 32, 33-46.

Käsermann, M.-L., Altorfer, A., \& Hirsbrunner, H.-P. (1998). Arousal and communication: II. Courses of activation during different types of interaction. Journal of Psychophysiology, 12, 60-75.

Käsermann, M.-L., Altorfer, A., \& Jossen, S. (1998). The effect of stressful and protective communicative events on the autonomic response in schizophrenic and healthy persons. International Journal of Psychopharmacology, 13 (Suppl. 1), 103-105.

KITNEY, R. I., \& Rompelman, O. (1980). The study of heart-rate variability. Oxford: Oxford University Press, Clarendon Press.
Pappillo, J. F., \& Shapiro, D. (1990). The cardiovascular system. In J. T. Cacioppo \& L. G. Tassinary (Eds.), Principles of psychophysiology: Physical, social, and inferential elements (pp. 456-512). Cambridge: Cambridge University Press.

Pennebaker, J. W., Hughes, C. F., \& O'Heeron, R. C. (1987). The psychophysiology of confession: Linking inhibitory and psychosomatic processes. Journal of Personality \& Social Psychology, 52, 781-793.

Porges, S. W., \& Bohrer, R. E. (1990). The analysis of periodic processes in psychophysiological research. In J. T. Cacioppo \& L. G. Tassinary (Eds.), Principles of psychophysiology: Physical, social, and inferential elements (pp. 708-753). Cambridge: Cambridge University Press.

SAID, S. I. (1984). Vasoactive intestinal polypeptide VIP: Current status. Peptides, 5, 143-150.

SidDle, D. A. T., \& TuRPIN, G. (1980). Measurement, quantification and analysis of cardiac activity, In I. Martin \& P. H. Venables (Eds.), Techniques in psychophysiology (pp. 139-246). New York: Wiley.

TieTze, U., \& SChENK, C. (1988). Halbleiter-Schaltungstechnik. Berlin: Springer-Verlag.

TuRPIN, G. (1989). Handbook of clinical psychophysiology. New York: Wiley.

van RavenswaaiJ-Arts, C. M. A., Kollée, L. A. A., Hopman, J. C. W., Stoelinga, G. B. A., \& van Geijn, H. P. (1993). Heart rate variability. Annals of Internal Medicine, 118, 436-447.

Zimmermann, H., Käsermann, M.-L., Altorfer, A., Jossen, S., \& FOPPA, K. (1998). Measurement and analysis of vocal aspects of communicative interaction [Abstract]. In Measuring Behavior '98: Proceedings of the Second International Conference on Methods and Techniques in Behavioral Research (p. 305). Wageningen, The Netherlands: Noldus Information Technologies.

\section{NOTE}

1. VASC Analyzer, which includes all features described in this article, can be use on Macintosh computers (e.g., Power Macintosh, G3, MacOS 8.6). For information about availability, contact the authors.

(Manuscript received December 18, 1998; revision accepted for publication November 2, 1999.) 